\title{
The Effects of Integrated Physical Education Class on Self-directed Learning Ability and Physical Education Class Attitude of Middle School Students
}

\author{
Deajung Lee \\ Jeonju Peonghwa middle school, Korea \\ dleownd23@hanmail.net
}

\begin{abstract}
The purpose of this study was to examine the effect of STEAM-based PE lessons on selfdirected learning abilities, a core competency of the 21st century, and on attitudes towards $P E$ classes related to physical education alienation and avoidance. To achieve this purpose, 6 classes out of 8 at J Middle School, J City, Jeollabukdo, South Korea were selected. The experimental and control groups, consisting of 87 and 88 students, respectively, were chosen from among the 238 first grade students by means of convenience sampling. The experimental group had PE classes based on STEAM for 14 weeks, whereas the control group were subjected to traditionally teacher-centered PE classes. The results of the study show that the experimental group displayed a significant difference in all the sub factors of attitude towards physical education classes and in all the sub factors of self-directed learning abilities as compared to the control group. In conclusion, PE classes based on STEAM have a positive effect on the students' attitude towards physical education classes and self-directed learning abilities. Based on the results, it suggests that efforts to combine STEAM education and physical education are needed.
\end{abstract}

Keywords: STEAM-Based, Physical education classes, Self-directed learning abilities, Attitudes

\section{Introduction}

STEAM schools and programs are being initiated around the United States [1]. STEAM refers to a convergence of different disciplines in education. It is the acronym for Science, Technology, Engineering, Arts, and Mathematics. The purpose of STEAM is to assimilate the principles of science and mathematics which develop logical thinking, and to achieve creative results by adding aesthetic elements, (Arts) based on creative design, (engineering) and technology. In particular, STEAM starts from one main theme, rather than subject-specific classes. It allows students to explore an issue from a variety of perspectives, and to develop creative problem-solving skills. In other words, STEAM curriculum focuses on interdisciplinary and inquiry-based learning.

However, there are only a few evidence-based studies to confirm these practical experiences. Thus relevant and reliable research is urgently needed to expand the emerging STEAM movement with accompanying activities [2]. Moreover, physical education has little

Article history:

Received (April 15, 2020), Review Result (May 22, 2020), Accepted (June 28, 2020) 
in common with STEAM, with very few examples of how it can be applied [3]. Therefore, this study aimed to improve the understanding of the connection between STEAM and physical education by examining the effect of STEAM-based physical education classes on middle school students' attitude towards physical education and self-directed learning abilities, and to examine various teaching and learning methods.

\section{Research methods}

\subsection{Research participants}

This study selected 6 classes in total. The experimental and control groups consisted of 3 classes each, of 87 students and 88 students, respectively, while practicing convenience sampling out of non-probability sampling. Learners completed a questionnaire to gauge their attitudes towards PE classes and self-directed learning abilities. A total of 178 final research participants were selected. A total of 4 students were excluded from the experimental and control groups as their responses in the questionnaire were not deemed reliable and sincere.

\subsection{Selection and organization of learning content}

STEAM can be problem-based and can consist of cooperative learning to apply and practice multidisciplinary knowledge so as to solve realistic problems [4][5]. Therefore, immediately after the start of the new semester in 2019, the curriculum council met to select the learning program to address the implementation of cooperative learning classes. Based on this, learning content was revised and supplemented after consultation between a major professor and two doctors of sport pedagogy. Specifically, this study selected the topics of Fine Dust and 1,000m running, (Science-5 periods, Arts-2 periods, Technology - Home Economics-2 periods, Physical Education-7 periods), Creative Expression Activities, (Science-2 periods, Technology - Home Economics-3 periods, Korean-4 periods, Physical Education-6 periods, Music-2 periods), Table Tennis, (Science-3 periods, Arts-2 periods, Technology • Home Economics-2 periods, Physical Education-6 periods, Society-2 periods), Tee Ball, (Science-3 periods, Arts-2 periods, Technology - Home Economics-2 periods, Physical Education-6 periods, Society-2 periods).

\subsection{Research process}

This study selected 4 sports disciplines; long-distance endurance running, creative expression activities, table tennis, and tee ball to verify the effect of physical education classes based on STEAM by conducting the classes for 14 weeks from March 11, 2019 to June 14, 2019. It took three weeks to complete the tasks related to each discipline because the curriculum related to each, coincided with other activities, rather than focus on each individual discipline separately. In order to confirm the results of this study, prequestionnaires were conducted for two days on March 4 and 5, 2019 after explaining physical education classes and research. And a post-test was performed for two days on June 17 and 18, 2019 after the application of flipped learning classes was completed. 


\subsection{Validity and reliability}

\subsubsection{Attitude towards physical education classes}

The explained variation of the whole dispersion regarding 6 sub factors of attitude towards physical education classes was 69.811 \% and KMO turned out to be .736, $\left(\chi^{2}=\mathbf{1 2 1 6 . 6 8 9}\right.$, $p<.000$ ). As for factor loading by sub factor, it turned out that each sub factor was valid, by showing health and physical strength with .834-.645, interpersonal relations with .863-.760, active participation with $.844-.712$, positive performance with $.808-.646$, negative emotions with .840-.668 and physical activities and movement with .916-.867. As for reliability test of internal consistency, it turned out that "health \& physical strength" was Cronbach's $\alpha=.785$, "interpersonal relations" was Cronbach's $\alpha=.791$, "active participation" was Cronbach's $\alpha=.749$, "positive performance" was Cronbach's $\alpha=.764$, "negative emotions" was Cronbach's $\alpha=.690$, and "physical activities \& movement" was Cronbach's $\alpha=.823$.

\subsubsection{Self-directed learning abilities}

The explained variation of the whole dispersion regarding 5 sub factors of self-directed learning abilities was $\mathbf{5 7 . 4 2 7} \%$ and KMO turned out to be $\mathbf{. 8 2 0},\left(\chi^{2}=\mathbf{1 1 0 0 . 4 9 8}, p<.000\right)$. As for factor loading by sub factor, it turned out that each sub factor was valid, by showing selfreflection with .803-.623, learning objective establishment with .784-.573, selection of learning strategies with .745-.610, desire for learning with .748-.597 and basic selfmanagement abilities with .846-.673. As for the reliability test of internal consistency, it turned out that self-reflection was Cronbach's $\alpha=.825$, learning objective establishment was Cronbach's $\alpha=.763$, selection of learning strategies was Cronbach's $\alpha=.689$, desire for learning was Cronbach's $\alpha=.647$, and basic self-management abilities was Cronbach's $\alpha=.610$.

\subsection{Data processing}

In this study, SPSS $21.0 \mathrm{~K}$ statistics program for Windows was used to process the results according to the purpose of this analysis. First, the validity and reliability analysis of questionnaire used exploratory factor analysis and Conbach's $\alpha$ according to a Varimax rotation. Second, the independent sample t-test was used to test homogeneity about pre-scores of attitude towards physical education classes and self-directed learning abilities between an experimental group and a control group. Third, to verify effect of Physical Education Classes based on STEAM of Self-directed Learning Abilities and Attitude towards Physical Education Classes, this study carried out Multivariate ANOVA, (MANOVA).

\section{Findings}

\subsection{Physical education classes and attitude towards physical education classes based on STEAM}

As shown in [Table 1], the Experimental group has higher average in all sub-factors of the attitude towards PE classes than the control group. 
Table 1. The mean and standard deviation of the attitude towards PE classes for the two groups

\begin{tabular}{|c|c|c|c|}
\hline Factor & Sub factor & Group & $\mathrm{M} \pm \mathrm{SD}$ \\
\hline \multirow{12}{*}{$\begin{array}{l}\text { Attitude } \\
\text { towards } \\
\text { physical } \\
\text { education } \\
\text { classes }\end{array}$} & \multirow{2}{*}{ Health and Physical Strength } & Experimental group & $17.25 \pm 2.78$ \\
\hline & & Control group & $14.97 \pm 2.08$ \\
\hline & \multirow{2}{*}{ Interpersonal Relations } & Experimental group & $13.11 \pm 2.12$ \\
\hline & & Control group & $11.34 \pm 1.68$ \\
\hline & \multirow{2}{*}{$\begin{array}{l}\text { Active Participation and Positive } \\
\text { Performance }\end{array}$} & Experimental group & $11.01 \pm 2.38$ \\
\hline & & Control group & $9.57 \pm 1.95$ \\
\hline & \multirow{2}{*}{ Positive Emotions } & Experimental group & $12.34 \pm 2.11$ \\
\hline & & Control group & $11.09 \pm 1.71$ \\
\hline & \multirow{2}{*}{ Negative Emotions } & Experimental group & $4.69 \pm 1.33$ \\
\hline & & Control group & $6.45 \pm 1.39$ \\
\hline & \multirow{2}{*}{ Physical Activities and Movements } & Experimental group & $8.56 \pm 1.62$ \\
\hline & & Control group & $7.49 \pm 1.10$ \\
\hline
\end{tabular}

To confirm the changes of attitude towards PE classes of students observed after the participation in PE classes based on STEAM between the two groups, MANOVA was carried out. According to the results, the experimental group which participated in PE classes based on STEAM showed improvement in all sub factors of attitude towards PE classes as compared with the control group. According to the results, the experimental group which participated in PE classes based on STEAM showed improvement in all sub factors of attitude towards PE classes as compared with the control group.

Table 2. The result of MANOVA and ANOVA on sub factors of attitude towards PE classes

\begin{tabular}{|c|c|c|c|c|c|c|c|}
\hline \multirow{2}{*}{ Sub factor } & \multicolumn{4}{|c|}{ MANOVA } & \multicolumn{3}{|c|}{ ANOVA } \\
\hline & Hoteling's 2 & $\mathrm{~F}$ & $p$ & $\eta^{2}$ & $\mathrm{~F}$ & $p$ & $\eta^{2}$ \\
\hline $\begin{array}{c}\text { Health and Physical } \\
\text { Strength }\end{array}$ & \multirow{6}{*}{.476} & \multirow{6}{*}{14.285} & \multirow{6}{*}{.000} & \multirow{6}{*}{.323} & 30.831 & .000 & .143 \\
\hline $\begin{array}{c}\text { Interpersonal } \\
\text { Relations }\end{array}$ & & & & & 36.441 & .000 & .165 \\
\hline $\begin{array}{l}\text { Active Participation } \\
\text { and Positive } \\
\text { Performance }\end{array}$ & & & & & 10.948 & .001 & .056 \\
\hline Positive Emotions & & & & & 25.764 & .000 & .122 \\
\hline Negative Emotions & & & & & 75.740 & .000 & .290 \\
\hline $\begin{array}{l}\text { Physical Activities } \\
\text { and Movement }\end{array}$ & & & & & 27.302 & .000 & .129 \\
\hline
\end{tabular}




\subsection{Physical education classes and self-directed learning abilities based on STEAM}

As shown in [Table 3], the Experimental group has higher average in all sub-factors of the Self-Directed Learning Abilities than the control group.

Table 3. The mean and standard deviation of the Self-directed learning abilities for the two groups

\begin{tabular}{|c|c|c|c|}
\hline Factor & Sub factor & Group & $\mathrm{M} \pm \mathrm{SD}$ \\
\hline \multirow{10}{*}{$\begin{array}{c}\text { Self-Directed Learning } \\
\text { Abilities }\end{array}$} & \multirow{2}{*}{ Desire for Learning } & Experimental Group & $13.49 \pm 2.53$ \\
\hline & & Control Group & $12.32 \pm 2.28$ \\
\hline & \multirow{2}{*}{$\begin{array}{l}\text { Learning Objective } \\
\text { Establishment }\end{array}$} & Experimental Group & $13.17 \pm 3.21$ \\
\hline & & Control Group & $10.94 \pm 2.86$ \\
\hline & \multirow{2}{*}{$\begin{array}{c}\text { Selection of Learning } \\
\text { Strategies }\end{array}$} & Experimental Group & $12.85 \pm 2.48$ \\
\hline & & Control Group & $11.01 \pm 2.71$ \\
\hline & \multirow{2}{*}{ Self-Reflection } & Experimental Group & $16.98 \pm 3.45$ \\
\hline & & Control Group & $13.99 \pm 3.34$ \\
\hline & \multirow{2}{*}{$\begin{array}{c}\text { Basic Self-Management } \\
\text { Abilities }\end{array}$} & Experimental Group & $11.18 \pm 2.03$ \\
\hline & & Control Group & $9.88 \pm 1.79$ \\
\hline
\end{tabular}

To compare the changes of self-directed learning abilities observed after the participation in PE classes based on STEAM, MANOVA was carried out. According to the results, the experimental group which participated in PE classes based on STEAM showed improvement in all sub factors of self-directed learning abilities as compared with the control group.

Table 4. The result of MANOVA and ANOVA on sub factors of Self-directed learning abilities

\begin{tabular}{|c|c|c|c|c|c|c|c|}
\hline \multirow{2}{*}{ Sub factor } & \multicolumn{4}{|c|}{ MANOVA } & \multicolumn{3}{|c|}{ ANOVA } \\
\hline & Hotelling's 2 & $\mathrm{~F}$ & $p$ & $\eta^{2}$ & $\mathrm{~F}$ & $p$ & $\eta^{2}$ \\
\hline Desire for Learning & \multirow{5}{*}{.201} & \multirow{5}{*}{7.281} & \multirow{5}{*}{.000} & \multirow{5}{*}{.167} & 15.962 & .000 & .079 \\
\hline $\begin{array}{l}\text { Learning Objective } \\
\text { Establishment }\end{array}$ & & & & & 22.510 & .000 & .108 \\
\hline $\begin{array}{c}\text { Selection of Learning } \\
\text { Strategies }\end{array}$ & & & & & 24.670 & .000 & .118 \\
\hline Self-Reflection & & & & & 19.239 & .000 & .094 \\
\hline $\begin{array}{c}\text { Basic Self-Management } \\
\text { Abilities }\end{array}$ & & & & & 15.605 & .000 & .078 \\
\hline
\end{tabular}

\section{Discussions}

\subsection{PE classes and attitude toward PE classes based on STEAM}

The reason why PE classes based on STEAM influenced the improvement of their attitude towards physical education classes is as follows.

First, PE classes based on STEAM increased students' academic motivation and participation. STEAM provides a practical environment. The practical environment enhances 
learning motivation by learning how to apply the knowledge they have learned and how it is related [6]. In particular, the practical environment gives students the opportunity to enjoy classes more than just learning or learning by listening only, and to find ways to effectively solve difficult tasks [2][7]. Moreover, physical education alienation occurs when motor functions are central [8]. Therefore, it seems that students' interest and learning motivation have been improved by knowing how the basic motor functions learned in physical activities are related to scientific theories, and making and using new tools based on mechanical principles. The self-determination theory of [9] suggests that an individual's motivation and performance will be maximized if the educational context that satisfies the needs for competence, autonomy, and relatedness is provided. These three needs are naturally satisfied as the students solve a task through student-centered cooperative learning in PE classes based on STEAM, increasing their motivation and participation.

Second, PE classes based on STEAM strengthened attitudes towards physical education classes by facilitating interaction between students, and students and teachers. The physical education classes based on STEAM encouraged team members to solve given tasks of abstract theories while sharing a variety of thinking strategies among themselves [10]. A study by [11] also thought that STEAM learning increases students' motivation, interaction with teachers, and effective learning. Students can achieve more when they study with friends rather than alone, and this process promotes the social development of students and promotes their voluntary participation in physical education classes [12]. Therefore, in PE classes based on STEAM, cooperative learning encourages students to voluntarily participate in tasks with their peers, and teachers serve as facilitators to enable a two-way communication rather than one-way communication. This makes students feel free in physical education classes, leading to their active participation and positive performance.

\subsection{PE classes based on STEAM and self-directed learning abilities}

The reason why PE classes based on STEAM has a positive effect on students' selfdirected learning abilities is as follows.

First, PE classes based on STEAM are based on problem-based learning. Problem-based learning allows students to participate in complex problems that cannot be solved with a single clue, apply new knowledge between different disciplines, and to reflect on their own learning [13]. In other words, PE classes based on STEAM are expected to enhance selfdirected learning abilities by providing students with the opportunity to solve the given problems by utilizing the knowledge learned in class, enabling them to think flexibly and evaluate the result of applying knowledge. This argument is supported by not only Zimmerman [14]'s study saying that self-directed abilities are improved with an open environment in which students can choose and apply knowledge, but also by Plucker et al. [15]'s study saying that students can improve self-directed learning abilities when they explore, observe, reflect, and ask specific questions in a STEAM environment.

Second, PE classes based on STEAM enhance self-efficacy. Students with high academic self-efficacy have high self-directed learning abilities because they use self-directed learning strategies such as learning strategies, motivational strategies, and cognitive strategies [16]. The factors contributing to self-efficacy improvement in PE classes based on STEAM can be found in the case of small-scale cooperative learning. Small-scale cooperative learning enhances self-efficacy by sharing and solving problems assigned to individuals, improving their abilities to cope with task stresses while achieving higher performance [17][18]. PE classes based on STEAM reduce the need for explanations and demonstrations important in 
traditional teacher-centered classes, and instead increase the time to practice given functions and to participate in problem-solving tasks through cooperative learning. This change in time allocation, especially in small-scale cooperative learning, implies that students feel that their peers can help them solve the problem of learning due to increasing feedback between them, thereby improving the achievement of tasks as they can concentrate on learning comfortably. This argument is supported by a study [19] suggesting that classes need to provide a supportive, encouraging environment and feedback to enhance students' self-efficacy.

\section{Conclusion}

An effort is required to apply STEAM to physical education. Many educational leaders have sometimes interpreted subjects and taught subject knowledge from a narrow viewpoint so that balanced teaching and learning methods have been requested in arts, science, and humanities [20]. In particular, physical education is struggling to solve students' alienation and avoidance problems despite numerous efforts. Thus, discussions have been made as to how the STEAM philosophy is suited to the field of physical education [21]. Therefore, a study needs to be conducted that explores important changes besides attitude towards physical education and self-directed learning abilities.

\section{References}

[1] T. Costantino, "STEAM by another name: Transdisciplinary practice in art and design education," Arts Education Policy Review, vol.119, no.2, pp.100-106, (2018) DOI: 10.1080/10632913.2017.1292973

[2] H. Thuneberg and H. Salmi, "To know or not to know: Uncertainty is the answer," Journal of Science Communication, vol.17, no.2, pp.1-28, (2018) DOI: 10.22323/2.17020201

[3] C. Li, W. K. K. Kam, and M. Zang, "Physical education teachers' behaviors and intentions of integrating STEM education in teaching," Physical Educator, vol.76, no.4, pp.1086-1101, (2019) DOI: 10.18666/tpe2019-v76-i4-9104

[4] A. B. Lynn, T. J. Moore Johnson, and Roehrig, "Integrated STEM education. STEM road map: A framework for integrated STEM education," New York: Routledge, pp.23-37, (2015)

[5] T. R. Kelley and J. G. Knowles, “A conceptual framework for integrated STEM education,” International Journal of STEM Education, vol.3, no.1, pp.1-11, (2016) DOI: 10.1186/s40594-016-0046-Z

[6] S. J. Eccles and A. Wigfield, "Motivational beliefs, values, and goals," Annu. Rev. Psychol, vol.53, pp.109132, (2002) DOI: 10.1146/annurev.psych.53.100901.135153

[7] T. Scruggs and M. Mastropieri, "Current approaches to science education: Implications for mainstream instruction of students with disabilities" Remedial and Special Education, vol.14, no.1, pp.15-24

[8] D. P. Johns and C. Dimmock, "The marginalization of physical education: Impoverished curriculum policy and practice in Hong Kong," Journal of Education Policy, vol.14, no.4, pp.363-384

[9] E. L. Deci and R. M. Ryan, "The what and why' N of goal pursuit: Human needs and the self-determination of behavior,” Psychological Inquiry, vol.11, pp.319-338, (2000) DOI: 10.1207/s15327965pli1104_02

[10] J. S. Kim, “STEAM pedagogical theory," Seoul: Yangseowon, (2012)

[11] D. M. Henrkisen, P. DeSchryver, Mishra, and Deep-Play Research Group, "Rethinking technology and creativity in the 21 st century transform and transcend: Synthesis as a trans-disciplinary approach to thinking and learning," Journal of Science Education and Technology, vol.59, no.4, pp.5-9, (2015) DOI: 10.1007/s11528-015-0863-9

[12] J. H. Kim, "Development and validation of a Korean version attitude scale for physical education," Ph.D. Dissertation, Kongju National University, (2004)

[13] C. E. Hmelo-Silver, "Problem-based learning: What and how do students learn?" Educational Psychology Review, vol.16, no.3, pp.235-266, (2004) DOI: 10.1023/b:edpr.0000034022.16470.f3 
[14] B. J. Zimmerman, "A social cognitive view of self-regulated learning," Journal of Educational Psychology, vol.81, no.3, pp.329-339

[15] J. A. Plucker, J. Guo, and A. Dilley, "Research-guided programs and strategies for nurturing creativity," In S. I. Pfeiffer, E. Shaunessy-Dedrick, and M. Foley-Nicpon, (Eds.), APA handbook of giftedness and talent, American Psychological Association, pp.387-397, (2018)

[16] B. J. Zimmerman, A. Bandura, and M. Martinez-Pons, "Self-motivation for academic attainment: The role of self-efficacy beliefs and personal goal setting," American Educational Research Journal, vol.29, pp.663-676

[17] A. Bandura, "Self-efficacy: The exercise of control," New York: Freeman

[18] D. Johnson and R. Johnson, "Making cooperative learning work," Theory into practice, vol.38, no.2, pp.67-73

[19] R. J. Sternberg and W. M. Williams, "How to develop student creativity," Alexandria, VA: Association for Supervision and Curriculum Development

[20] C. F. Quigley and D. Herro, "Finding the joy in the unknown: Implementation of STEAM teaching practices in middle school science and math classrooms," Journal of Science Education \&Technology, vol.25, pp.410426, (2016) DOI: 10.1007/s10956-016-9602-z

[21] H. E. Erwin, "Full STEAM ahead in physical education," The Journal of Physical Education, Recreation and Dance, vol.88, no.1, pp.3-4, (2017) DOI: 10.1080/07303084.2016.1249759

\section{Author}

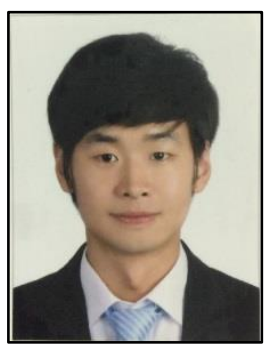

\section{Daejung Lee}

$\mathrm{PhD}$ in education

JeonJu PyeongHwa Middle School, (P.E.) Teacher 